\title{
O Livro de Falas no Brasil e nos E.U.A: percursos literários e tradutórios
}

\author{
Giovana Cordeiro Campos de Mello (UFF/Labestrad)
}

\begin{abstract}
Resumo: O objetivo deste trabalho é refletir, a partir de um prisma historiográfico e cultural, sobre o processo de publicação de O Livro de Falas ou Kalunbungu, de Edimilson de Almeida Pereira, no Brasil, em 1987, em edição do autor, e nos Estados Unidos, na revista Callaloo, em 1996. A voz do poeta começou seu caminho em 1985, com Dormundo, seguido pela publicação de O Livro de Falas, e continuou seu percurso com a publicação de poesias, ensaios e literatura infantojuvenil, entre outros, tendo o universo afro-brasileiro como tema de reflexão. Os textos do referido pesquisador, ensaísta e poeta conseguiram extrapolar as fronteiras nacionais, tendo sido traduzidos e publicados em paises como a Inglaterra, Itália, Espanha Alemanha e Estados Unidos. A presente pesquisa ilumina parte dessa trajetória, tomando como base conceitos dos Estudos da Tradução e procurando pensar a tradução de elementos da cultura brasileira para o contexto norte-americano e o processo mais amplo da publicação de poesia afro-brasileira em solo nacional e estrangeiro.
\end{abstract}

Palavras Chave: O Livro de Falas; Estudos da Tradução; Historiografia; Poesia Afro-Brasileira

\section{A Literatura Afro-Brasileira e seu Lugar no Sistema Literário}

Pesquisas demonstram que mais da metade da população brasileira é composta de negros ou pardos (IBGE, 2010), sendo inegável, portanto, o papel dos afro-brasileiros na formação da cultura nacional. O estudo do discurso afro-brasileiro em todas as suas manifestações constitui não somente a chance de se reconhecer a força de um segmento ainda marginalizado em nossa sociedade, mas também a oportunidade de se entender a própria identidade nacional.

A nomenclatura "literatura afro-brasileira" geralmente tem sua base em dois critérios básicos: o étnico, que vincula a obra à origem do autor, e o temático, 
que vincula a obra a seu conteúdo, por assim dizer. Entretanto, estudiosos, como o próprio Edimilson de Almeida Pereira, objeto de nosso estudo, argumentam que tais critérios não abrangem a formação da literatura brasileira, que apresenta afro-brasileiros escrevendo sob padrões europeus e não-negros lidando com temas afro-brasileiros. $\mathrm{O}$ autor defende o uso de um "critério mais pluralista" que possa "demonstrar a Literatura Afro-brasileira como uma das faces da Literatura Brasileira - esta mesma sendo percebida como uma unidade constituída de diversidades" (Pereira, 1995, 1) ${ }^{1}$. Nessa linha, há trabalhos que discutem a conjunção de um número maior de fatores. Eduardo de Assis Duarte, por exemplo, defende a conjunção dinâmica de cinco grandes fatores: a temática, a autoria, a linguagem, o ponto de vista e o público-leitor. Assim, entram em jogo, por exemplo, as tradições culturais transplantadas para o Brasil, o "conjunto de valores morais e ideológicos que fundamentam as opções até mesmo vocabulares presentes na representação" (2007, p. 107) e "um público específico, marcado pela diferença cultural e pelo anseio de afirmação identitária” (p. 109). Para Duarte,

a afro-brasilidade tornar-se-á visível já a partir de uma discursividade que ressalta ritmos, entonações, opções vocabulares e, mesmo, toda uma semântica própria, empenhada muitas vezes num trabalho de ressignificação que contraria sentidos hegemônicos na língua (p. 109).

Gilvan Procópio Ribeiro, no prefácio da obra Negras Raízes Mineiras - Os Arturos, de Edimilson de Almeida Pereira e Núbia de Magalhães Gomes, afirmava que:

É já um truísmo hoje, falar no resgate da voz e do ponto de vista dos oprimidos. Contudo, apenas se inicia o trabalho efetivo de trazer à tona o que sempre se buscou ocultar. Num país como o nosso em que as tradições parecem estar gradativamente entregues às traças, o resgate das diversas histórias, em suas sobrevivências atuais, é fundamental (1988, p. 11).

A partir da abertura proporcionada pelos estudos culturais, pouco a pouco tomava forma uma maior mobilização da comunidade afro-brasileira no sentido de uma afirmação da especificidade do discurso afro-brasileiro em termos étnicos, psicológicos, históricos e sociais.

O encontro que ocorreu entre povos bem distintos, decorrente das grandes navegações, já foi bastante discutido. A forma como o negro africano foi representado nesse contexto, porém, ainda merece discussão mais ampla. A bibliografia

1 <http://press.jhu.edu/demo/callaloo/18.4de_almeida_pereira9_p.html> 
existente nos permite afirmar que a sociedade brasileira foi formada, a princípio, pelos brancos (europeus), negros (africanos) e índios. Os portugueses trouxeram consigo os referentes culturais europeus de sua época, nos quais a escravatura negra se fazia presente. Tal hierarquia lusitana, embora diluída pelo passar do tempo, ainda sobredetermina a sociedade brasileira moderna, na maneira pela qual o negro é visto e representado.

Exemplos da cor negra associada a julgamentos negativos são fáceis de encontrar na literatura. Susani França (2001) cita Gil Vicente como exemplo desse processo, uma vez que o autor qualificava de feios os camponeses de pele escura, demonstrando uma tradição, não muito questionada anteriormente, de ligar a palavra "negro" a características pejorativas. Contrapõem-se a esses exemplos descrições que evidenciam a robustez do negro, mas que, por outro lado, acabam por desvalorizar o intelecto com a supervalorização do corpo. Ou seja, valoriza-se o porte, mas os valores culturais continuam a ser ignorados. Pereira, em Ardis da Imagem (2001), por exemplo, discute que a imagem da mulata sensual e a do negro viril levam a uma noção do mito da potência sexual, o que somente reitera a imagem do negro enquanto produto.

Com base nos estudos sobre a literatura e a cultura brasileiras, não só a figura dos negros era bastante estereotipada, mas também o modo de viver dos africanos, o que remete diretamente à questão cultural. Os portugueses não estavam preparados para aceitarem as formas de organização social dos negros, as quais não eram inspiradas no modelo político-social europeu. O resultado foi o da negação do negro como cidadão durante séculos, e, consequentemente, a desvalorização de suas especificidades culturais.

Há um processo de "estereotipização", no qual o negro é visto como um ser inferior, incapaz de ser considerado um formador da sociedade nacional. Segundo Maria Nazareth Fonseca (2000):

As imagens construídas sobre o negro, na cultura brasileira, não se distanciam muito daquelas produzidas em outros espaços economicamente desenvolvidos a partir de mão de obra escrava. Nesses espaços, o negro, elemento importante na aceleração da acumulação de capital, transformou-se em mão de obra barata, em utensílio a ser utilizado nos engenhos, nas minas e, posteriormente, nas fábricas, tendo o seu valor calculado pelo que valia como mercadoria de troca (p. 89).

O próprio Edimilson afirma que esse "deslocamento dos negros para a condição de coisa" (2001, p. 117) se faz presente tanto na forma como se des- 
creve os negros como na forma pela qual os negros são tratados. Por meio desse processo, pouco da especificidade cultural da comunidade afro-brasileira foi abordada e podemos dizer que a tendência de se retratar as faixas mais abastadas da população na literatura nacional ajudou a reforçar a imagem do negro como escravo e, consequentemente, a abafar a voz desse importante componente da sociedade brasileira.

A abolição da escravatura não representou uma oportunidade real de igualdade dos negros para com os brancos em termos sociais, mas uma nova forma de escravidão, a da pobreza, uma vez que o negro do período pós-abolição continuou a ocupar posições de trabalho subalternas e mal remuneradas. Segundo Fonseca (2000):

Livre da escravidão, mas vitimado por intensa pobreza e preconceitos e não protegido por qualquer política de integração à sociedade, ficou à margem dos projetos de identidade nacional ou neles só pôde figurar enquanto força de trabalho, que sustenta a mesma ordem que o exclui (p. 90).

À medida que novos modelos literários surgiram, como o naturalismo, por exemplo, começou a ser promovida a inserção dos menos favorecidos da sociedade brasileira nas expressões literárias e o quadro começou, aos poucos, a apresentar mudanças. A alteração na expressão literária revela o desenvolvimento da própria sociedade como um todo, uma vez que os vários sistemas, literário e social, estão interligados. Com o passar do tempo, novas relações de trabalho foram sendo estabelecidas, a população foi se multiplicando e o país se definindo com uma nação mais independente. Nesse quadro, os afro-brasileiros, cada vez mais, sentiram a necessidade de afirmar sua identidade, sufocada por séculos de dominação da cultura branca ocidental.

Em entrevista dada a Ana Maria Reis, Pereira resume o estado da literatura afro-brasileira nos idos de 2001, mas que ainda é aplicável ao momento atual:

As poéticas negroafricanas [...] têm se insinuado [...] pois têm de superar 'séculos de espera', abrir os cânones e conferir outros significados aos verbos para mostrar-se. Se a música vem permitindo essa apresentação há mais tempo, por sua vez, a poesia escrita e cantofalada segue ritmo mais lento, mas em curso (p. 3).

Pensando-se em termos sistêmicos, é possível traçar um panorama do estado da literatura afro-brasileira em relação à literatura brasileira como um todo, tomando como base a proposta da teoria dos polissistemas (polysystem theory), de 
Itamar Even-Zohar (1979). A literatura é um dos sistemas que compõem o polissistema da cultura e sociedade brasileiros. Dentro do sistema da literatura brasileira estão os vários subsistemas literários que o compõem. Em posição central estão localizadas as obras consideradas canônicas, que são facilmente publicadas e lidas, e que seguem a ideologia dominante, no caso do Brasil, ainda bastante ligada à cultura branca. Já a literatura afro-brasileira ocupa uma posição periférica, até por representar a descontinuidade do modelo dominante, porém, em movimento, ou seja, em processo gradual de fortalecimento. Muitas vezes, ainda cabe aos próprios autores a impressão e a distribuição dos seus trabalhos, o que restringe bastante o escopo de alcance das obras - foi esse o caso da $1^{\text {a }}$. edição da obra em foco neste trabalho, O Livro de Falas, primeiramente publicada como edição do autor em 1987.

Os subsistemas, porém, não estão em posição estanque, havendo um jogo de forças no qual as literaturas periféricas ameaçam constantemente o centro dominante. Assim, a literatura afro-brasileira está lutando por uma posição mais privilegiada, o que nos leva a descrevê-la, segundo percepção desenvolvida em conjunto com Oliveira ${ }^{2}$, como uma literatura em deslocamento, cujos produtores cada vez mais reivindicam seu espaço. A literatura afro-brasileira não está abalando o centro no sentido de uma inversão de posições, mas o trabalho de escritores afro-brasileiros e a intensificação do interesse dentro da academia pelo estudo das expressões dos grupos minoritários revelam, no mínimo, uma força no sentido periferia-centro, demonstrando uma tendência para a modificação do status quo.

\section{A Poesia de Edimilson de Almeida Pereira: O Livro de Falas, ou Kalumbungu}

Na produção de sua obra poética, Pereira aborda o universo afro-brasileiro, com seus costumes, rituais, divindades e mitos. A religiosidade é um dos elementos marcantes e a experimentação realizada pelo poeta relaciona-se com a percepção e compreensão do mundo com base na experiência emocional, histórica e social do sujeito negro. O próprio poeta, em entrevista a Steven F. White, descreve parte de seu processo de escrita: "Senti a necessidade de internalizar ou de engolir a beleza dos mitos e, então, retorná-los para o mundo [...] com algum significado extra" (1996, p. 45). A atitude de Pereira é a da reinvenção do passado afro-brasileiro, da reafirmação da cultura e da comunidade negras, mas de uma forma transgressora,

2 Durante encontros para o desenvolvimento da monografia O Livro de Falas, de Edimilson de Almeida Pereira: jogos de força nos contextos brasileiro e norte-americano, 2002. 
o que nos leva a considerá-lo um "tradutor de tradições", expressão usada por Oliveira (2000) para se referir à prática dos irmãos Campos e à dos escritores que, à moda dos rabinos antigos (midrashistas), criam seus textos a partir de infindáveis interpretações que fazem das tradições que lhes são significativas (OLIVEIRA, 2000).

O Livro de Falas on Kalumbungu (1987) é uma coletânea de diálogos com os mitos que formam a base do candomblé, religião afro-brasileira cujos elementos básicos são originários da tradição iorubá. Muitos dos escravos trazidos para o Brasil entre o final do século XVIII e início do século XIX pertenciam à região africana do povo iorubá. Em conjunto com esses escravos, chegaram seus costumes, seus rituais e também a religião dos orixás, que são os intermediários entre o deus supremo - Olorum - e os seres humanos. Diferentemente dos santos cristãos, as divindades do candomblé apresentam personalidades próprias, com características humanas. Cada traço dessa personalidade é associado a um elemento da natureza e da sua cultura: o fogo, a água, os instrumentos de ferro etc.

Desde o princípio do regime escravocrata, as religiões afro-brasileiras se desenvolveram na forma do sincretismo com o catolicismo. Como forma de manterem suas tradições, mas também devido à forte repressão a seus costumes pelos colonizadores, os quais consideravam os cultos africanos como sendo feitiçaria, os negros passaram a associar os orixás a santos católicos. Dessa forma, Iansã, orixá dos ventos e tempestades, foi sincretizada com Santa Bárbara. Já Ogum, considerado o senhor dos metais na mitologia iorubá, é identificado com Santo Antônio ou São Jerônimo. No processo de transposição das divindades para o contexto brasileiro o número de orixás foi reduzido.

Kalunbungu significa "caixa mágica" e os poemas que compõem O Livro de Falas são distribuídos em três seções. Na primeira, cada poema começa com uma epígrafe, retirada do livro O Duplo e a Metamorfose: a Identidade Mítica em Comunidades Nagô (1983), de Monique Augras, estudiosa francesa radicada no Brasil cujo interesse recai nas religiões afro-brasileiras. As epígrafes introduzem os diferentes orixás, temas dos poemas do livro. Ao leitor são apresentados textos que abordam o espaço da ligação entre a tradição e o moderno na cultura afro-brasileira. As epígrafes são o mito original e o poema, então, dialoga com o mito. Como exemplo desse processo de "reinvenção", tomemos o poema Amor:

"Temanjá é, por definição, a mãe, a senhora das origens.

... Reina sobre 'todas as águas do mundo' doces e salgadas.

... deusa das águas primevas que são 'fons et origo', matrizes de todas as possibilidades de existência”" 


\section{Amor}

És pura indagação de meus seios. Ainda que o céu se quebre não te condenarei. As águas, minhas filhas, abrem sete canoas, mas por elas não te perderás. Meu ventre respira a sabedoria dos peixes, este amor de algas nos olhos. Suplico-te não mais que a humildade das flores entregues à chuva.

A epígrafe apresenta o mito original, o orixá Iemanjá, cultuado no Brasil como o orixá das águas do mar. Sua figura é ligada à feminilidade, à beleza, à maternidade e à fertilidade. Sua representação espelha a função materna: mulher jovem e de seios salientes. O poema é a voz do orixá a dialogar com os homens, daí o uso dos possessivos ("minhas filhas" e "meu ventre"). O poema de Pereira trabalha o mito dando-lhe voz, permitindo o seu diálogo com o leitor. Na relação epígrafe/poema, mito original/sua reinvenção, encontramos toda a criatividade do poema e o trabalho do poeta de "engolir a beleza dos mitos para [...] retorná-los ao mundo [...] com um significado extra" (1996, p. 45). Esse mesmo procedimento é adotado para os outros poemas, os quais foram primeiramente publicados em edição do autor (1987), posteriormente traduzidos por White para a revista Callaloo (1996) e cuja edição mais recente é a da Mazza Edições (2008).

\section{O Poeta no Brasil}

A produção poética de Pereira pode ser considerada como duplamente marginalizada no contexto do sistema literário nacional. Em primeiro lugar, por ser a poesia atualmente pouco lida. Além do fato de o público leitor no Brasil ser ainda reduzido, muitos dos que efetivamente consomem literatura preferem a ficção em prosa. Além disso, vivemos em uma sociedade capitalista, logo, muitas editoras acabam por não demonstrar tanto interesse na promoção de autores não tão conhecidos, os quais ficam com a responsabilidade de investirem na publicação e divulgação de suas obras. Recentemente, essas condições têm sido enfrentadas com ajuda de uma importante "aliada tecnológica" - a internet. Mas no caso de nosso objeto de estudo, cabe colocar que a época de publicação era a década 1980, quando nem internet nem redes sociais tinham força em nosso país. A distribuição das obras constituía um grande problema, uma vez que um autor sozinho não tinha meios para alcançar um vasto número de leitores. As obras acabavam por serem lidas por um número restrito de pessoas e alguns leitores mais especializados. Foi o que ocorreu com O Livro de Falas, publicado pelo próprio autor em 1987 e com tiragem limitada. Isso não significa que na época não havia grande produção de 
poesia no Brasil, o problema é que as publicações ocorriam de forma "subterrânea”, ou seja, marginal (PEREIRA, 2000, p. 3). A segunda razão para a posição marginal de Pereira à época remete à questão da negritude propriamente dita. Os autores negros e mestiços, muitas vezes, se veem obrigados pelas circunstâncias a funcionarem como sociólogos, antropólogos e historiadores, papeis que surgem da necessidade premente de se apresentarem, sob a perspectiva afro-brasileira, a sua história no Brasil.

Uma questão que merece ser analisada é a da patronagem. Com o desenvolvimento do pensamento sobre a tradução, no campo dos Estudos da Tradução, André Lefevere (1992) cunha o termo patronagem (patronage). O autor considera que a cultura e a sociedade são o ambiente do sistema literário e a patronagem, nesse contexto, pode ser entendida como o poder exercido por instituições, pessoas, partidos políticos etc. que determinam, de fora do sistema literário, o que pode ou não ser feito em termos de literatura (LEFEVERE, 1992, p. 15). Os tradutores, ao aceitarem um patrocínio, ligam-se à ideologia dos patrocinadores. A patronagem pode ser não-diferenciada, quando todos os fatores - econômico, ideológico e de status - são exercidos por um mesmo e único patrocinador; ou diferenciada, quando o sucesso econômico predomina sobre os demais fatores, o que nem sempre vem acompanhado de status (caso dos bestsellers, por exemplo). Quando um autor publica em revistas especializadas ou ele próprio publica suas obras, os autores e os críticos se autorregulam, uma vez que os textos são produzidos por e para eles próprios. Nesse caso, a figura do patrocinador é representada pelos próprios poetas/críticos que são, muitas vezes, seus próprios editores, caracterizando uma patronagem não-diferenciada.

O processo abordado acima abrange a publicação e circulação de parte da obra de Pereira nas décadas de 1980-90, que foi realizada a partir de revistas especializadas ou pelo grupo D'Lira, formado por pesquisadores, poetas, jornalistas e escritores, e responsável pela publicação e circulação de obras como Dormundo (1985), Árvore dos Arturos \& Outros Poemas (1988) entre outras. O principal objetivo do grupo era o da divulgação da arte, e não o lucro, uma vez que eles mesmos produziam e distribuíam o folheto Abre Alas, no centro comercial da cidade de Juiz de Fora - MG. No caso de Pereira, uma vez que, na década de 1990, parte de sua obra já começava a ser publicada pela Mazza Edições, podemos considerar que uma mudança na forma da patronagem também tinha lugar. Apesar de a Mazza Edições ser uma editora voltada para publicações que retratem o universo afro-brasileiro, ainda assim constitui um estabelecimento que tem, além dos objetivos ideológicos, fins comerciais e, consequentemente, tende a ter um maior âmbito de penetração para as obras ali publicadas. 
Assim, ao admitirmos, como Even-Zohar (1979), que os sistemas estão interligados e sob um jogo de forças constante, podemos dizer que o sistema periférico que representava a literatura de origem africana na década de 1990 já lutava contra as forças conservadoras do centro, porém, sem força suficiente para inverter relações até então estabelecidas (o que ainda se mantém nos dias atuais, embora deva ser observado que a força contrária exercida pela literatura afro-brasileira se encontra atualmente mais fortalecida).

\section{A Revista Callaloo}

A revista Callaloo é uma das publicações da editora da Universidade Johns Hopkins, localizada em Baltimore, E.U.A. Na década de 1990 era uma publicação de circulação internacional e trimestral. Atualmente, são cerca de quatro edições anuais. Destina-se à publicação de estudos literários africanos e afro-americanos, podendo ser encontradas obras originais e estudos críticos sobre a cultura negra. A revista foi criada em 1976 como resultado do desenvolvimento do campo de estudos chamado estudos afro-americanos, nascido dos ideais propostos pelo projeto dos Black Studies e pelos estudos culturais. Entre os objetivos da Callaloo está o de dar espaço a produções que abordem a negritude e colaborar para o reconhecimento de suas especificidades.

Na edição de 1996, usada neste trabalho, consta que o critério de escolha envolvia: "poetas afro-brasileiros que reinventam as divindades associadas com os diversos grupos religiosos de base africana [...]" e que "reinventam o passado de forma nem fácil e previsível, nem inteiramente tradicional” (WHITE, 1996, p. 70-71). Como vimos, os poemas de Pereira em O Livro de Falas possuem as características mencionadas. Portanto, por criar poemas pautados na reinvenção de tradições africanas, Pereira, com o seu O Livro de Falas, fez-se presente entre os autores brasileiros publicados na Callaloo.

Os exemplos utilizados para análise neste trabalho se referem à primeira parte de O Livro de Falas, traduzidas por Seteve F. White para a revista Callaloo, cuja edição contém, ainda, uma entrevista com o autor relativa ao processo de produção dos poemas. White esteve no Brasil em 1994 para a realização de sua tradução, o que possibilitou a ele discutir o texto com o autor e, ao mesmo tempo, conviver com a cultura afro-brasileira em solo brasileiro. 


\section{A Tradução e sua Posição Periférica}

Os Estados Unidos constituem um país economicamente forte, cujo sistema literário apresenta a tendência de se manter impermeável às influências estrangeiras, configurando um sistema conservador. Essa característica por si só faz com que a literatura traduzida ocupe uma posição periférica dentro do sistema literário norte-americano. Além disso, a produção cultural dos afro-americanos também sofreu um processo de marginalização, tendo ocupado uma posição periférica no sistema literário até que, aos poucos, fosse exercida uma força contrária à posição hegemônica. Pensando no processo de entrada da obra de Pereira no momento de sua publicação, 1996, podemos pensar que a literatura afro-brasileira representada pela poesia de Pereira era, no contexto norte-americano, duplamente marginalizada: primeiro por se tratar de uma tradução e, segundo, por lidar com assuntos relativos à cultura africana. Contudo, publicações como a da revista Callaloo, que discutem a realidade sob um ponto de vista dos negros, funcionam como uma força contrária à dominação do centro do sistema literário por uma ideologia marcadamente branca.

\section{A Patronagem não-diferenciada e a Tradução da obra}

O termo reescritura (rewriting) foi usado por Lefevere (1992) para abordar, entre outros, a manipulação exercida sobre os textos fonte com o objetivo de fazer com que esses "originais" se ajustem ou não às correntes poetológicas e ideológicas dominantes na época de produção da tradução. Partindo do princípio de que toda tradução é uma reescritura (rewriting), a tradução dos poemas que compõem O Livro de Falas constitui uma nova reescritura dos mitos afro-brasileiros. Assim como há uma diferença linguística entre as reescrituras de Pereira e de White, o veículo de distribuição também é distinto, uma vez que houve a passagem da forma de livro para a de uma revista literária. A mudança do veículo de circulação da obra gerou uma maior especificidade do público-alvo, que passa a ser também o da revista, ou seja, o de leitores profissionais da academia que lidam com a cultura africana em geral. Ao mesmo tempo, os artigos publicados são produzidos por sujeitos negros e/ou que lidam com a cultura africana no contexto acadêmico. Logo, temos um quadro em que leitores profissionais escrevem para leitores também profissionais.

Muito embora a revista Calalloo tivesse em 1996 um grande escopo de distribuição não apenas dentro dos E.U.A., mas também de relevo internacional, trata-se de uma revista destinada ao contexto acadêmico, não atingindo, portanto, as camadas populares. Logo, no que tange à obra de Pereira nos Estados Unidos, 
verifica-se uma patronagem não-diferenciada, uma vez que se tem um sistema autorregulador com interesses bastante específicos.

Segundo Lawrence Venuti (1995), tomando como base o pensamento de Friedrich Schleiermacher (1813), seriam duas as possíveis estratégias a serem usadas pelo tradutor. A primeira, por ele criticada, é a da domesticação (domestication), com a produção de um texto fluente, com o consequente apagamento das diferenças linguísticas e culturais do texto fonte em prol da tentativa de produzir um texto consumível. Já a segunda estratégia, a defendida pelo estudioso, é a da estrangeirização (foreignization), que tem por objetivo deixar visíveis as marcas da origem estrangeira do texto, com a importação das diferenças linguísticas e culturais.

Como vimos, a patronagem não-diferenciada é característica de um sistema autorregulador, no qual leitores/reescritores da academia reescrevem para eles próprios. Como esse é o caso das traduções estudadas, concluímos que os leitores não-profissionais não são o objetivo das traduções. É possível afirmar, portanto, que o fator econômico não foi determinante para o processo tradutório. Assim, as estratégias tradutórias não foram diretamente condicionadas pela imagem que o leitor não-profissional tem da cultura brasileira com um todo. Ao mesmo tempo, uma vez que a revista visa à integração do sujeito negro e de sua cultura, marginalizados tanto no sistema literário como no sistema social, o contexto que cerca a realização da tradução de O Livro de Falas, a princípio, parece favorecer uma tradução estrangeirizadora, isto é, uma tradução que visa o respeito às características culturais e linguísticas da obra, ainda que isso produza empecilhos à leitura.

Ao analisarmos a tradução realizada por White, intitulada Book of Voices (1996), da primeira parte de O Livro de Falas, observamos que as estratégias adotadas oscilam entre domesticação e estrangeirização. É preciso lembrar, como aponta Venuti (1995), que o contexto norte-americano é bastante impermeável ao diálogo intercultural, havendo uma preferência por procedimentos que tornem a leitura mais fluente, sem empecilhos a um leitor já acostumado a receber textos assim traduzidos. Contrariando o status quo do contexto de chegada da tradução, White opta, por exemplo, por não adotar a grafia inglesa para os orixás. Desse modo, Exú, Oxum, Oxumaré entre outros não têm a grafia do " $\mathrm{x}$ " alterada para "sh" (como Eshu, Shango, etc.); ou seja, não houve uma postura de aproximar a escrita aos sons do contexto de chegada, mas sim um movimento para permitir o estabelecimento de possíveis estranhamentos.

Outro exemplo, bem interessante, que aponta para um movimento tradutório de diálogo entre culturas, encontra-se no poema "Mau Olhado", no qual é usado o vocábulo mestressala, bastante comum na cultura brasileira, mas não no 
contexto norte-americano. Além de manter o termo na grafia portuguesa, White ainda acrescentou uma nota explicativa: "Mestressala is the principal male dancer who accompanies the female flag bearer in a samba school". Mesmo que possa ser argumentado que a nota é um recurso problemático (pois "quebra" a leitura do texto) e que a nota de White é um pouco redutora dos sentidos de mestressala no candomblé, defendemos que seu uso nesse contexto constitui um recurso de introdução do termo no universo receptor da obra traduzida, o que enfatiza uma preocupação do tradutor em salientar a origem estrangeira do texto. Não houve, a nosso ver, pelo menos em termos culturais, uma tentativa de se buscar no contexto da cultura norte-americana algo que se assemelhasse ao funcionamento do termo na cultura brasileira. Na epígrafe do mesmo poema aparece um ingrediente muito usado na cultura (afro-)brasileira - o dendê. A imagem do "coco do dendezeiro" é mantida em "coconut of the dendê palm", novamente propiciando uma troca de saberes.

No entanto, embora White tenha apresentado uma preocupação com o respeito ao contexto fonte da obra, também adota procedimentos domesticadores. Na segunda epígrafe do poema "Visitação", há uma inversão da posição do sujeito da sentença, que aparece no final da oração devido a questões de efeito poético. White, contudo, preferiu antepor o sujeito ao verbo, no intuito, ao que parece, de obedecer a uma ordem mais natural dos elementos da sentença em inglês:

"... da lama e das águas primordiais surgiu um montículo de laterita vermelha..." (PEREIRA, 1987, grifos nossos).

"... a bill of red laterite came forth from the mud and primordial Waters..." (PEREIRA, 1996, grifos nossos).

No mesmo poema temos "O cavalo sou eu...", que foi vertido por White por "I am the horse..."(PEREIRA, 1996). O texto fonte evidencia o animal, colocando o vocábulo "cavalo" como sujeito da oração. White altera a ordem dos elementos na frase, usando o termo como predicativo do sujeito, embora fosse possível a construção "The horse is me". Provavelmente a alteração foi efetuada para deixar o texto mais fluente na língua de chegada.

\section{Considerações finais}

A partir de nosso estudo, consideramos que a literatura afro-brasileira encontra-se ainda em deslocamento, por representar uma força no sentido periferia- 
-centro, que tenta ocupar um lugar mais próximo do centro dominante do sistema literário brasileiro. Essa movimentação no sentido periferia-centro não se verifica apenas na esfera da academia, uma vez que a obra de Pereira já na década de 1990 iniciava seu percurso no mundo editorial. Além disso, a publicação de obras afro-brasileiras fora do contexto nacional representa a possibilidade de mostrar uma parte significativa da literatura brasileira.

Observamos que a tradução realizada por Steven F. White é domesticadora no que tange às estruturas linguísticas, até em função das exigências da própria língua inglesa; contudo, ela é estrangeirizante no que se refere às características culturais. A manutenção das diferenças entre a cultura fonte e a meta no decorrer do processo tradutório, aliada à escolha do referido autor, cuja temática aborda outras características do universo brasileiro que não as já cristalizadas no contexto norte-americano, leva-nos a concluir que as traduções aqui estudadas contribuem para a construção de uma imagem para o Brasil menos estereotipada e mais abrangente. A abordagem dos traços culturais pertencentes à cultura estrangeira no contexto da tradução, característica de uma tradução estrangeirizadora, aliada a uma escolha de autores que possam compreender vários aspectos de uma mesma cultura, constitui a esperança de uma forma de representação mais ampla e menos preconceituosa da identidade cultural do país de onde provém o texto traduzido.

\section{Referências bibliográficas}

CAMPOS, Giovana Cordeiro. O Livro de Falas, de Edimilson de Almeida Pereira: jogos de força nos contextos brasileiro e norte-americano. 2002. (Monografia). Instituto de Ciências Humanas e de Letras, UFJF.

DUARTE, Eduardo de Assis. Literatura Afro-brasileira: um conceito em construção. In AFOLABI, Niyi; BARBOSA, Márcio; RIBEIRO, Esmeralda (Orgs.) A mente afro-brasileira. Trenton-NJ, EUA / Asmara, Eritréia: África World Press, 2007, p. 103-112.

EVEN-ZOHAR, Itamar. "Polysystem theory”. In: Poetcis today, Tel Aviv, v. 1, n. 1/2, 1979. p. 287-310.

FONSECA, Maria Nazareth Soares (Org.). Brasil afro-brasileiro. Belo Horizonte: Autêntica, 2000.

FRANÇA, Susani S. L. Literatura reforça estigma do escravo. O Liberal, Belém, p. 18, 14 out. de 2001.

GOMES, Núbia P. Magalhães, PEREIRA, Edimilson de Almeida. Negras raízes mineiras: os arturos. 2. ed. Belo Horizonte: Mazza, 2000.

LEFEVERE, André. Translation, rewriting and the manipulation of literaty fame. London, New York: Routledge, 1992. 
OLIVEIRA, Maria Clara Castellões de. O pensamento tradutório judaico: Franz Rosenzweig em diálogo com Benjamim, Derrida e Haroldo de Campos. 2000 - Tese (Doutorado em Letras: Estudos Literários) - Faculdade de Letras, UFMG.

PEREIRA, Edimilson de Almeida. O livro de falas ou kalunbungu: achados da emoção inicial. Juiz de Fora: Edição do autor, 1987.

. From O Livro de Falas (Book of Voices). Translated by Steven F. White. Callaloo. Baltimore: Johns Hopkins University Press, 1996. p. 33-43

. "An interview with Edimilson de Almeida Pereira". Callaloo. Baltimore: Johns Hopkins University Press, 1996. Entrevista concedida a Steven F. White. p. 44-54.

Panorama da literatura afro-brasileira. In: Callaloo. v. 18. n. 4. John Hopkins University Press, 1995.

. "Edimilson, um poeta local, homem do mundo" (entrevista concedida a Ana Maria Reis). Página eletrônica: http://www.jfservice.com.br/arquivo/estacao/artistas/2000/09 /20-Edimilson/. Consulta realizada em 19 de julho de 2001.

GOMES, Núbia Pereira de Magalhães. Ardis da imagem: exclusão étnica e violência nos discursos da cultura brasileira. Belo Horizonte: Mazza; PUCMinas, 2001.

VENUTI, Lawrence. Invisibility. In: Translator's invisibility: a history of translation. New York: Routledge, 1995. p. 1-42. 